\title{
FATTY INFILTRATION OF THE MEDIAN NERVE
}

\author{
P. M. Yeoman, Bath, England
}

From the Royal National Orthopaedic Hospital and Institute of Orthopaedics, London and Stanmore

Mesodermal tumours of peripheral nerves were classified by Stout (1949) who mentioned lipoma as a possible example. Lipomata are generally encapsulated tumours which have been described in the palm of the hand by Straus (1931), Posch (1956) and Stack (1960). Some have caused pressure on peripheral nerves and were reported by Richmond (1953), Campbell and Wulf (1954), White and Hanna (1962); others have been associated with neurofibromatosis and macrodactyly (Kanavel 1932, Werthemann 1952).

Brunelli (1964) made a careful survey of the literature in his report of one case of fatty infiltration of the median nerve. The three cases reported here are further examples of fatty infiltration of the median nerve which were referred to the Peripheral Nerve Injury Clinic at the Royal National Orthopaedic Hospital during the last eleven years.

Case 1--In 1953 a girl aged eleven was referred with a diffuse swelling of the left palm extending into the ring finger. The swelling was noticed at birth but had gradually increased in size and

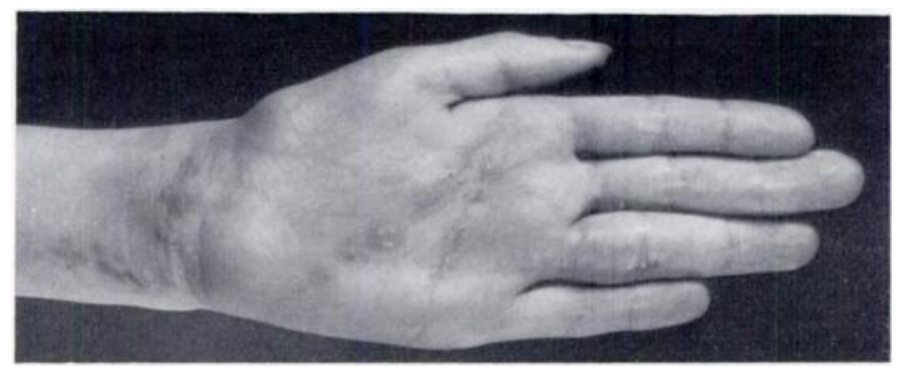

Flci. 1

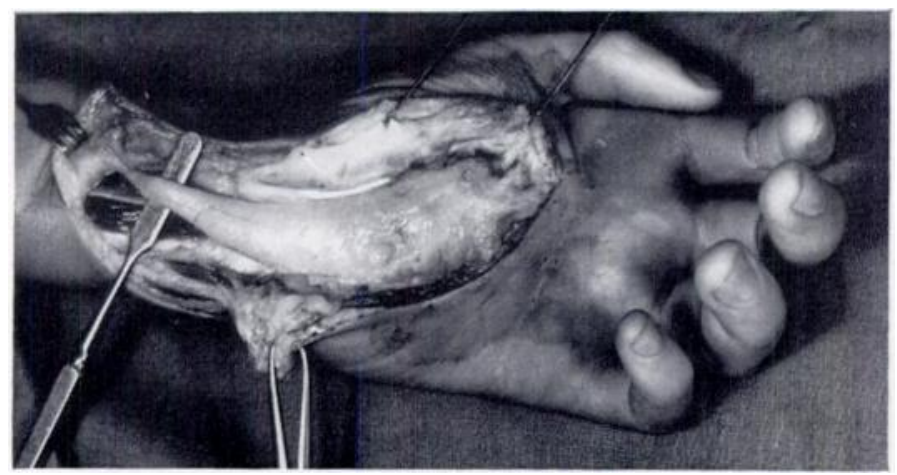

FIG. 2

Case 1. Figure 1-Diffuse swelling of the palm and base of the ring finger. There is wasting of the thenar eminence due to paralysis of the thenar muscles resulting from the first exploration. Figure 2-Extensive fatty infiltration of the median nerve shown after division of the flexor retinaculum.

was associated with intermittent pain in the base of the ring finger. One year previously exploration of the swelling had revealed a lipoma arising within the median nerve, and during the course of the dissection a digital nerve to the first cleft had been divided and repaired. On examination there was a diffuse swelling in the palm of the hand extending over the palmar 
aspect of the proximal phalanx of the ring finger (Fig. 1). There was paralysis of the thenar muscles, and there were hypoalgesia and hypoaesthesia of adjacent aspects of the first cleft.

Operation-At exploration the median nerve was found enormously swollen by a soft smooth yellow fatty tumour which started 2 centimetres proximal to the wrist and extended into all the digital branches (Fig. 2). Attempts to resect and repair the defect were abandoned in view of the extensive nerve involvement, but a small piece was resected for histological examination.

Histology (Dr H. A. Sissons)-The section consisted of fat and fibrous tissue with a few nerve bundles surrounded by fibro-fatty tissue.

Progress - In 1960 a small subfascial lipoma was removed from the region of the olecranon process at the left elbow. Histological examination showed fibro-fatty tissue with an indefinite lobular pattern. There was no evidence of neurofibroma.

At a recent follow-up examination the patient said that she had not noticed any increase in size of the swelling in the left palm and ring finger. The function of the hand was impaired not only by the soft bulky tumour in the palm but by the paralysis of the thenar muscles and impaired skin sensibility in the adjacent aspects of the thumb and index finger.

Case 2-In 1963 a girl aged sixteen was referred with a diffuse swelling of the left palm. Three years previously she had complained of nocturnal "pins and needles" over the distribution of the median nerve, and in 1962 the swelling was explored. A lipoma was found involving

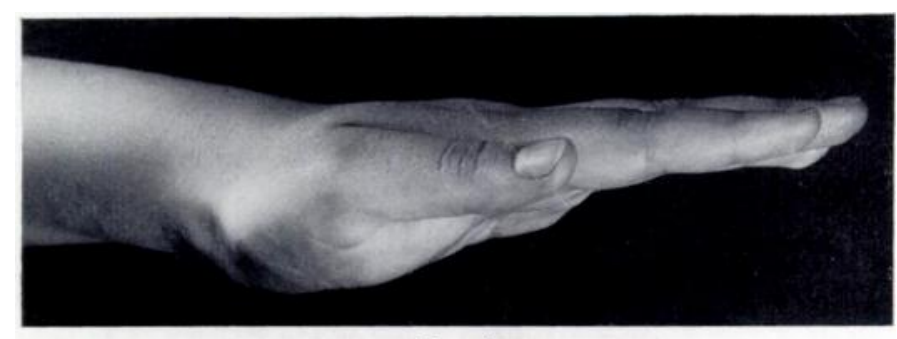

FIG. 3

Case 2-Diffuse swelling of the palm of the hand.

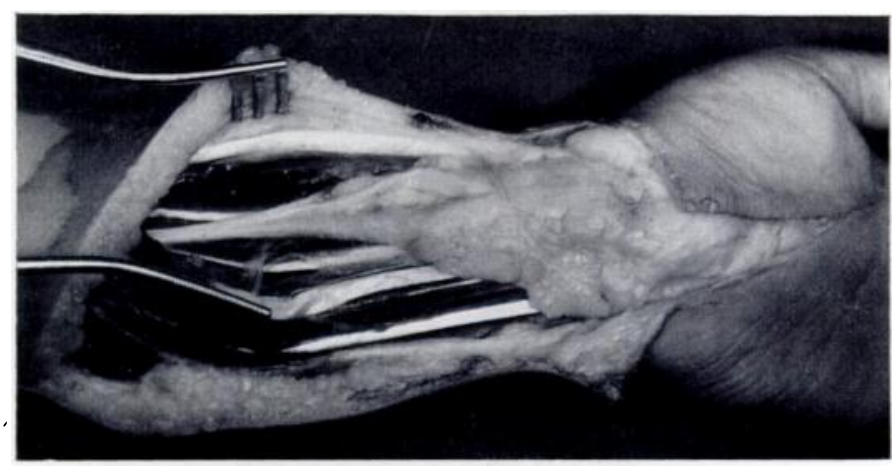

FIG. 4

Case 2-Fatty infiltration of the entire median nerve including the digital branches. The flexor retinaculum has been divided.

the median nerve and during the course of the dissection a digital nerve was divided. A piece of tissue was resected. Histological examination ( $\mathrm{Dr} \mathrm{H}$. A. Sissons) showed a few slender and rather fibrotic nerve bundles which were widely separated by fibro-fatty tissue. There was no encapsulating layer. The appearances suggested a diffuse fibro-fatty overgrowth rather than an encapsulated benign tumour. 
On examination there was a soft smooth tumour extending across the wrist into the palm (Fig. 3). Voluntary power was normal, but there were hypoaesthesia and hypoalgesia in adjacent aspects of the ring, middle and index fingers.

Operation-At exploration a large fatty tumour, 17 centimetres long, was found extending across the wrist into the palm (Fig. 4). A few fasciculi were traced through the tumour but the dissection was abandoned when the fatty tissue became intimately dispersed through the fasciculi and nerve fibres. A small specimen was taken for biopsy.

Histology-The material was similar to the previous section and consisted of fibro-fatty tissue, numerous small blood vessels but no nerve bundles.

Case 3-In 1963 a woman aged twenty-one complained of a swelling at the base of the left index finger which had been present since childhood. On examination there was a smooth lobulated tumour overlying the proximal phalanx of the index finger. Voluntary power was normal but the bulky tumour restricted active flexion of the finger.

Operation-At exploration a fatty tumour was seen to infiltrate the digital nerve on the radial side of the index finger and it extended into the main trunk of the median nerve. The dissection was abandoned because of the extensive nerve involvement.

\section{DISCUSSION}

The three patients described in this report had no clinical manifestations of neurofibromatosis and there was no suggestion of macrodactyly on radiographic examination of the hands. The clinical signs mimicked those of a compound palmar ganglion, a soft encapsulated lipoma and a haemangioma but the diagnosis was made at exploration. It is suggested that fatty infiltration of the median nerve is a congenital defect which may cause symptoms of a "carpal tunnel syndrome," and that care is required in attempting a biopsy owing to the vulnerable position of the separated nerve bundles.

\section{SUMMARY}

1. Three cases of fatty infiltration of the median nerve are reported.

2. One patient had symptoms of median nerve compression.

3. The intimate association of fibro-fatty tissue within the nerve precludes enucleation of the swelling.

I am grateful to Sir Herbert Seddon for permission to publish Cases 1 and 2, to Mr Donal Brooks for Case 3, and to $\mathrm{Dr} \mathrm{H}$. A. Sissons for the histological reports.

\section{REFERENCES}

Brunelli, G. (1964): Lipoma interfibrillare del nervo mediano con sindrome da compressione nel canale del carpo. Minerva Ortopedica, 15, 211.

Campbell, C. S., and Wulf, R. F. (1954): Lipoma Producing a Lesion of the Deep Branch of the Radial Nerve; Case Report. Journal of Neurosurgery, 11, 310.

Kanavel, A. B. (1932): Hypertrophy of Digits in Neurofibromatosis. Archives of Surgery, $25,317$.

Posch, J. L. (1956): Tumors of the Hand. Journal of Bone and Joint Surgery, 38-A, 517.

Richmond, D. A. (1953): Lipoma Causing a Posterior Interosseous Nerve Lesion. Journal of Bone and Joint Surgery, 35-B, 83.

Stack, H. G. (1960): Tumours of the Hand. British Medical Journal, i, 919.

Stout, A. P. (1949): Atlas of Tumor Pathology. Section 2. Fascicle 6. Tumors of the Peripheral Nervous System. Washington, D.C.: Armed Forces Institute of Pathology.

Straus, F. H. (1931): Deep Lipomas of the Hand. Annals of Surgery, 94, 269.

Werthemann, A. (1952): Die Entwicklungsstörungen der Extremitäten. In Handbuch der Speziellen Pathologischen Anatomie und Histologie. Herausgegeben von O. Lubarsch, F. Henke und R. Rössle. Band 9 6, Seite 378. Berlin: Springer Verlag.

White, W. L., and Hanna, D. C. (1962): Troublesome Lipomata of the Upper Extremity. Journal of Bone and Joint Surgery, 44-A, 1,353.

VOL. 46 B, NO. 4, NOVEMBER 1964 